\title{
Partidos Políticos no controle de Constitucionalidade Concentrado: do acesso universal à pertinência temática
}

\section{Policy parties abstract judicial review: from Universal acces to Thematic Pertinence}

\author{
Gabriela Perrelli de Melo ${ }^{l}$ \\ Flávia Danielle Santiago Lima \\ José Mário Wanderley Gomes Neto ${ }^{3}$
}

\begin{abstract}
RESUMO
Os partidos políticos possuem ampla legitimidade para propor ações diretas do controle de constitucionalidade perante o Supremo Tribunal Federal.? A função primeira dos partidos políticos é a de representar os cidadãos, servindo de meio de comunicação - e de pressão entre os representados e o governante. Por democracia ser, ao mesmo tempo, um ideal e uma prática, deve existir um compromisso com o esforço de aproximar cada vez mais a representação ideal da representação/forma como são concebidas as instituições, a fim de propiciar a verdadeira liberdade e igualdade entre as pessoas. Neste quadro, parte-se da seguinte pergunta: as agremiações estão cumprindo com sua função representativa, propondo ações judiciais de acordo com o que se definem para os seus eleitores? Para responder à questão proposta, a partir do método indutivo, propõe-se uma análise qualitativa de cinco ações
\end{abstract}

\footnotetext{
1 Advogada. Mestra em Direito pela Universidade Católica de Pernambuco. Graduação em Direito pela Universidade Católica de Pernambuco. Participou do Programa Institucional de Bolsas de Iniciação Científica (PIBIC) da Universidade Católica de Pernambuco na qualidade de bolsista, desenvolvendo pesquisa em Ciência Política e Direito Constitucional, obtendo menção honrosa. Apresentou a referida pesquisa no XXIII Congresso Nacional do Conpedi, em João Pessoa, também obtendo menção honrosa. Foi monitora da cadeira de Direito Constitucional I em 2012. Estágio Docência em Direito Constitucional III. Atuação e temas de interesse: Judicialização da Política, Ativismo Judicial, Controle de Constitucionalidade, Partidos Políticos, Democracia, Representação e Diálogos Institucionais. Universidade Católica de Pernambuco; gabrielaperrelli@ hotmail.com.

2 Pós-Doutorado em Direito pela Universitat de València/ Espanha. Mestre e Doutora em Direito Público pela Universidade Federal de Pernambuco/UFPE. Professora da Faculdade de Direito da Universidade de Pernambuco (UPE/Recife). Professora permanente do Programa de Pós-Graduação em Direito da Faculdade DAMAS (MESTRADO). Líder do Grupo de Pesquisa JUSPOLÍTICA - Diálogos, Historicidades e Judicialização de Políticas (Direito/UPE), e Pesquisadora no Grupo PRAETOR - Grupo de estudos sobre Poder Judiciário, Política e Sociedade (Ciência Política/UFPE), registrados no Diretório Geral de Grupos de Pesquisa do CNPQ. Advogada da União, desde 2003 (AGU). Áreas de pesquisa: Judicialização da Política, Ativismo, Autocontenção e Política Judicial, Diálogos Institucionais e Políticas Públicas. Academia: upe.academia.edu/FlaviaDanielleSantiagoLima. E-mail: flavia-santiago@uol.com.br.

${ }^{3}$ Advogado, Cientista Político, Professor e Pesquisador do U.DATA - Laboratório de Pesquisas Empíricas em Direito (UNICAP). Possui graduação em Direito pela Universidade Católica de Pernambuco (2000), mestrado em Direito pela Universidade Federal de Pernambuco (2003) e doutorado em Ciência Política pela Universidade Federal de Pernambuco (2015). Atualmente é professor da Universidade Católica de Pernambuco. Tem experiência nas áreas de Direito e Ciência Política, atuando principalmente nos seguintes temas: democracia, controle de constitucionalidade, instituições políticas, judicialização da política, comportamento judicial e acesso à justiça. ResearchGate: https://www.researchgate.net/profile/Jose_Mario_Gomes Orcid: https://orcid.org/00000002-4003-856X. E-mail: josemwgomes@ gmail.com.
} 
propostas pelos partidos, confrontando o objeto das ações com o conteúdo dos estatutos das respectivas legendas, de modo a indicar se haveria um desvio de finalidade na provocação da revisão judicial, se constatada a não correspondência com os interesses políticos supostamente representados pelo partido. Portanto, a pesquisa é apoiada por uma pesquisa bibliográfica e documental. A hipótese geral é que os partidos políticos se afastam de seus interesses, a justificar a análise, pelo Supremo Tribunal Federal, da necessária pertinência temática entre as ações propostas e os estatutos partidários.

\title{
PALAVRAS-CHAVE:
}

Partidos Políticos. Função representativa. Legitimidade ativa. Supremo Tribunal Federal. Controle de Constitucionalidade.

\begin{abstract}
Political parties have a largest legitimacy to put forward direct actions of judicial review on Brazilian Supreme Court (STF). The primary function of political parties is to represent the citizens, serving as a means of communication - and pressure - between the represented and the ruler. Because democracy is both an ideal and a practice, there must be a commitment to the effort to bring the ideal representation ever closer to the way in which institutions are conceived in order to provide true freedom and equality between people. In this context, we start from the following question: are the associations fulfilling their representative function, proposing lawsuits according to what define themselves for their voters? To answer the proposed question, we start from the inductive method, we proceeded to the qualitative analysis of five lawsuits proposed by the parties, comparing the purpose of the actions with the content of the statutes of the respective parties, in order to indicate if there would be a misuse of purpose in provoking the judicial review. Therefore, the research is supported by a bibliographical and documentary survey. The general hypothesis is that political parties deviate from their interests, justifying the Brazilian Supreme Court's analysis of the necessary thematic pertinence between the proposed lawsuits and the party statutes.
\end{abstract}

\section{KEYWORDS:}

Political parties. Representative rule. Active legitimation. Brazilian Supreme Court. Judicial Review.

\section{INTRODUÇÃO: A REPRESENTAÇÃO POLÍTICO-PARTIDÁRIA ENTRE TEORIA E PRÁXIS}

Do Estado de Direito para o Estado Constitucional, o Poder Legislativo cedeu seu papel de destaque para o Poder Judiciário. O ordenamento jurídico passou a ser orientado não pelas 
leis, mas pela Constituição, fonte de interpretação e aplicação de todas as normas e atos normativos, que consiste, também, em parâmetro de validade.

Como consequência da autonomia do Judiciário e de sua autoridade enquanto poder constitucional, o séc. XX e o mundo presenciaram o fenômeno da judicialização da política: questões tradicionalmente resolvidas no âmbito do Legislativo e do Executivo passaram a ser discutidas por juízes e tribunais, sobretudo no exercício da jurisdição constitucional.

No Brasil, a abertura política vivida durante o processo constituinte de 1987-1988 propiciou o desenvolvimento do controle de constitucionalidade abstrato, ao instituir não apenas uma variedade de ações diretas, como também ao ampliar o rol de legitimados ativos e, por conseguinte, incrementar a possibilidade de impugnação de atos normativos elaborados pelos poderes majoritários.

Nesse sentido, destacam-se os partidos políticos.

As agremiações, em virtude do seu relevante papel para o regime democrático - são representantes do povo, a quem e por quem o governo se presta -, foram contempladas com legitimidade bastante extensa para demandar no Supremo Tribunal Federal (STF). Basta que tenham ao menos um representante no Congresso para que estejam autorizados a propor as ações diretas do controle de constitucionalidade. Em especial, judicializam sem a obrigação de comprovar nexo entre a demanda e as suas atividades institucionais - filtro este denominado pertinência temática, construído pela jurisprudência para outros atores contemplados com o direito de acesso à justiça constitucional.

Por outro lado, a Ciência Política fala da crise de representatividade sofrida pelos referidos partidos (MAIR, 2003). A sociedade civil não consegue se reconhecer nos seus representantes e está descrente da política; por conseguinte, afasta-se dessa esfera, caindo num ciclo vicioso, no qual o abismo que os separa cresce cada vez mais.

É por esse motivo que surge o seguinte problema de pesquisa: na jurisdição constitucional, estão os partidos cumprindo com sua função representativa, propondo ações judiciais de acordo com aquilo que se definem para os seus eleitores? 
Considera-se que a função primeira das agremiações políticas é a de representar os cidadãos, servindo de meio de comunicação - e de pressão - entre os representados e o governante. Outrossim, democracia é, ao mesmo tempo, um ideal e uma prática (DAHL, 2001; PITKIN, 1985). Deve-se o empenho no esforço de aproximar cada vez mais a representação ideal da representação/forma como são concebidas as instituições, a fim de propiciar a verdadeira igualdade e liberdade entre as pessoas.

Buscando respostas para a pergunta, o artigo propõe analisar os comportamentos dos partidos políticos, tendo como referencial as ações do controle de constitucionalidade propostas no STF (ADI's e ADPF's) no período de 1988 a 2014, disponíveis no site do Supremo Tribunal Federal.

Após a apresentação dos resultados das pesquisas anteriores de Sobral Neto (2014) e Melo e Gomes Neto (2015), será feita a análise comparativa dos casos, confrontando o objeto das ações com o conteúdo dos estatutos das respectivas legendas partidárias, de modo a indicar por que naquelas ações do controle concentrado haveria um desvio de finalidade da revisão judicial pela não correspondência com os interesses políticos supostamente representados pelo partido. Serão discutidos cinco casos do controle concentrado, os quais versarão sobre ADIs e entre eles estará a ADPF 172, a ação judicial de processo objetivo em que se discutiu a guarda do menino Sean Goldman. Os casos foram selecionados por um critério simples: contemplar agremiações partidárias dos mais distintos espectros ideológicos.

O estudo parte de uma abordagem teórica, com o método indutivo, combinado com uma análise qualitativa de casos. A pesquisa é apoiada por um levantamento bibliográfico e documental. Assim, combina-se métodos das disciplinas de Direito e Ciência Política; em outras palavras, levando em consideração teorias normativas e positivas. As primeiras prescrevem os critérios que devem ser observados em qualquer decisão; as segundas perguntam quais fatores motivam as decisões judiciais no mundo real, por serem atos políticos (v.g. WHITTINGTON et al., 2008). 


\section{DEMOCRACIA E JURISDIÇÃO CONSTITUCIONAL ABSTRATA: COMPREENDENDO O PAPEL DOS PARTIDOS POLÍTICOS}

Partidos políticos constituem organizações destinadas a congregar eleitores que participam dos mesmos interesses ou das mesmas ideologias (CRETELLA JÚNIOR, 1989). Eles congregam não apenas função burocrática, mas, em especial, uma representativa, já arraigada no próprio conceito das agremiações. Esta é a sua função primeira: representar. Contudo, antes de adentrar na questão representativa, algumas considerações acerca dos partidos políticos são necessárias.

Tal como explica Giovanni Sartori (1982), não se escreveu sobre partidos políticos para, depois, colocar em prática essa forma de representação; ao revés, ao passo que os partidos foram surgindo e se desenvolvendo, a ciência passou a se ocupar deles e de suas características. Nesse sentido, as análises sobre o que são e para que servem necessariamente devem passar pelo estudo do seu desenvolvimento. Para Sartori, há três premissas: a) os partidos não são facções; b) um partido é "parte-de-um-todo"; c) os partidos são canais de expressão.

A distinção conceitual entre partidos e facções foi a primeira das condições favoráveis para que aqueles pudessem se desenvolver. A confusão entre os conceitos, existente a princípio, gerava uma grande resistência contra a palavra "partido". Ocorre que facção envolvia e até hoje possui um significado pejorativo, remetendo a um grupo movido a interesses particulares, mesquinhos. Coube a Burke, em 1774, argumentar pela primeira vez no sentido da distinção, embora não fosse ali o fim da repulsa. Assim, partido seria um grupo de homens, reunidos para promoção do interesse nacional, orientados por algum princípio com o qual todos concordam (BURKE, 2012).

Um outro fator importante para a aceitação dos partidos foi o pluralismo, com "a compreensão de que a diversidade e a dissensão não são necessariamente incompatíveis com a ordem política, nem necessariamente a perturbam" (SARTORI, 1982, p. 33-34), mas, ao contrário, podem levar a uma vida melhor. É neste momento, no qual a diversidade 
e a dissenção ganham louvor, que partidos passam a ser mais bem aceitos, deixando de ser considerados "partes contra o todo" para serem "partes do todo", nas expressões de Sartori. ${ }^{4}$

Por fim, a terceira e última premissa tem a ver com as atividades dos partidos: são canais de expressão. Além da função representativa, eles possuem a chamada "função expressiva": apresentam-se como alternativas para transmitir às autoridades os desejos do povo e oferecem os canais para articulação, comunicação e implementação das demandas dos governados. Mas não tão somente. Segundo Sartori (1982, p. 50), os partidos "oferecem algo que nenhuma máquina ou pesquisa de opinião pode oferecer: transmitem reinvindicações apoiadas por pressões. O partido lança seu próprio peso nas reinvindicações a que se sente obrigado a fazer eco".

Com relação à jurisdição constitucional brasileira, os partidos políticos atualmente se apresentam como legitimados a demandar no controle concentrado de constitucionalidade, como decorrência do processo constituinte de 1987-8, que veio a ampliar o rol de legitimados a acionar o mecanismo de retificação legislativa no Brasil.

Dentre os grupos organizados da sociedade brasileira que exerceram influência no processo constituinte- e por esse motivo chamados de grupos de pressão (CARVALHO et al, 2011) -, os partidos políticos foram contemplados com a legitimidade para acionar a revisão abstrata, caso tenham ao menos um representante no Congresso Nacional.

Saliente-se: legitimados universais, posto que não necessitam comprovar pertinência temática quando do ajuizamento das ações diretas. São dotados de ampla capacidade processual. Isso porque a própria ideia do princípio majoritário contempla a visão da relevância dos partidos políticos para a democracia moderna, ao passo que eles representam não apenas a sua classe/instituição, mas todo o eleitorado.

Os partidos políticos são, portanto, grupos que exercem e sofrem pressão, reunidos, na visão burkeana, para a promoção do interesse nacional. São capazes de formular e expressar demandas de maneira a influenciar os resultados do sistema político, ao mesmo tempo em que

\footnotetext{
${ }^{4}$ Essas expressões de Giovanni Sartori devem-se à semântica. “Quando 'parte' se torna 'partido' temos, então, uma palavra sujeita a duas influências semânticas: a derivação de partire, dividir, de um lado, e a associação com tomar parte, e portanto com participação, do outro". (SARTORI, 1982, p. 24) [grifos do autor]
} 
se consagram como mandatários públicos. Pautam-se, pois, pelos respectivos eleitorados, os quais, por sua vez, também equivalem a grupos de interesse.

No processo constituinte de 1987-1988 os partidos políticos atuaram mais uma vez como grupo de pressão e lograram inclusão no rol dos legitimados ativos para a propositura da ação direta de inconstitucionalidade (ADI’s). Posteriormente, também foram inseridos para as ações declaratórias de constitucionalidade (ADC’s) e arguições de descumprimento de preceito fundamental (ADPF's).

No desenho constitucional brasileiro, estão autorizados a propor as ações do controle direto de constitucionalidade o Procurador-Geral da República, o Presidente da República, as Mesas do Senado Federal, da Câmara dos Deputados, das Assembleias Legislativas dos Estados e do Distrito Federal, os Governadores, o Conselho Federal da Ordem dos Advogados do Brasil (OAB), os partidos políticos, as confederações sindicais e as entidades de classe com âmbito nacional (art. 103). As preocupações em torno do excesso de demandas, sobretudo dos atores da sociedade civil sempre foram grandes. E para reduzi-las, foi criado, na jurisprudência do STF o "filtro" da pertinência temática, que estabelece a "necessidade de identificação de nexo entre a norma impugnada e as atividades institucionais dos requerentes como condição de admissibilidade" do processo de controle concentrado. (LIMA e GOMES, 2018, p. 236). Governadores e as Mesas das Assembleias Legislativas dos Estados passaram a ter de obedecer à nova regra jurisprudencial, e entidades de classe e confederações sindicais tiveram seus conceitos minimamente disciplinados.

Embora pessoas jurídicas de direito privado, a legitimidade para os partidos políticos foi concebida, pelo STF, como universal, em virtude de serem instituição imprescindível ao desenvolvimento do regime democrático, de sorte que, sobre elas não incidiria a restrição jurisprudencial derivada do vínculo de pertinência temática. Aliás, compreende o Tribunal que a representação partidária nas ações diretas, “constitui prerrogativa jurídico-processual do diretório nacional do partido político, que é - ressalvada deliberação em contrário dos estatutos partidários - o órgão de direção e de ação dessas entidades no plano nacional” (BRASIL, 1994), mesmo que a norma impugnada tenha sua amplitude limitada a Estado ou Município (BRASIL, 2002). 
No caso, reconhece-se que os partidos políticos consubstanciam o principal mecanismo para o exercício dos direitos políticos, eis que representantes do povo, com funções definidas pela Constituição Federal e pelo artigo $1^{\circ}$ da Lei 9.096/95: velar pelo Estado Democrático de Direito, pela autenticidade do sistema representativo e defender os direitos fundamentais definidos na Constituição Federal.

A preocupação primordial na democracia sempre foi a participação do povo na organização do Estado e na atuação do governo, por considerar que ele, em decorrência natural, ao expressar livremente sua vontade, então soberana, saberia velar pela liberdade e a igualdade (DALLARI, 2010, p. 151). Os partidos políticos, por sua vez, compõem um instrumento imprescindível no processo de formação da vontade política do povo: o instituto da representação. É pelo povo e para o povo que devem governar. O escopo precípuo de todo e qualquer partido político corresponde ao zelo pelo cumprimento do sistema representativo, não apenas como conjunto de regras, mas, principalmente, na efetiva representatividade que ele proporciona (LUCON e VIGLIAR, 2011, p. 574).

Porém, em virtude da complexidade das sociedades modernas, conferiu-se um grande poder aos representantes, dotando-os de autonomia, a fim de conferir efetividade ao sistema democrático. Como as políticas públicas, em virtude dessa complexidade, passaram a requerer cada vez mais a tomada de decisão em um menor espaço de tempo, não seria possível exigir que os representantes apenas atuassem após o consentimento dos seus representados (DALLARI, 2010, p. 156-158). Aos partidos foi dada a autonomia e liberdade de decidirem por aqueles que representam, os quais neles votam e assim os tornam representantes na expectativa de ver cumpridos o que esses políticos propõem.

Tamanha autonomia e liberdade, porém, constituem um risco. Tal como concebida a atual engenharia do mandato, seu exercício sujeita-se apenas à consciência do representante (DA SILVA, 2014, p. 141). O mandatário político não está vinculado aos seus eleitores, de quem não recebe instrução alguma. Se receber, não tem obrigação jurídica de atender, não tendo, por isso, de prestar contas, ainda que politicamente o faça, tendo em vista o interesse na reeleição.

Faltam mecanismos de responsividade e accountability que possam conferir aos partidos políticos responsabilidade por aquilo que fazem. Por isso, a existência do fenômeno a 
seguir comentado, a que se chama de crise de representatividade. A essência do mandato, tal como concebida atualmente, constitui risco à democracia, atacando um de seus princípios típicos e norteadores, constitutivos do regime: a representação.

\section{A CONFORMAÇÃO JURÍDICA DA REPRESENTAÇÃO POLÍTICA: OS ESTATUTOS PARTIDÁRIOS}

O sistema eleitoral brasileiro, então embasado na combinação de democracia representativa e participação direta, é eminentemente partidário. O partido político é "uma forma de agremiação de um grupo social que se propõe organizar, coordenar e instrumentar a vontade popular com o fito de assumir o poder para realizar seu programa" (DA SILVA, 2014, p. 394) [destaque nosso]. O partido corresponde a um dos canais que permitem a população se expressar nos acontecimentos políticos e decisões de governo. Configuram, ainda, inafastável requisito de elegibilidade para a obtenção de um mandato popular.

A eleição gera, portanto, em favor do eleito, o mandato político representativo, que constitui elemento básico do regime democrático. O poder é conferido pelo povo, seu titular e em nome de quem se deve agir, aos seus representantes, periodicamente eleitos. Por isso a expressão "mandatários públicos". No mandato se consubstanciam os princípios da representação e da autoridade legítima (NUNES JÚNIOR, 2014, p. 104). Pelo primeiro, o poder é conferido pelo povo, seu titular e em nome de quem se deve agir, aos seus representantes, periodicamente eleitos. O segundo princípio, por sua vez, está relacionado à teoria da imputação do Direito Administrativo: o Estado carece de vontade real e própria, pelo que atua mediante seus agentes, dando-lhe condições de, através da vontade humana, manifestar-se.

No sistema jurídico, partidos políticos foram entendidos como pessoas jurídicas de direito privado, que adquirem personalidade jurídica de acordo com a lei civil, o que os obrigam a registrar os seus estatutos no Registro Civil de Pessoas Jurídicas. Contudo, além dessa obrigação, eles também deverão, ulteriormente, registrar os seus estatutos perante o Tribunal Superior Eleitoral. 
É-lhes assegurada autonomia para definir sua estrutura interna, organização e funcionamento, segundo consta do artigo 17 da Constituição Federal e do artigo $3^{\circ}$ da Lei 9.096/95. Tal prerrogativa, porém, não é absoluta: os partidos hão de se organizar e funcionar em harmonia com o regime democrático, além de sua estrutura interna também ficar sujeita ao mesmo princípio (DA SILVA, 2014, p. 408-409).

Pela norma constitucional e pelo artigo $5^{\circ}$ da Lei 9.096/95, deverão ter caráter nacional, com ações exercidas de acordo com o seus respectivos estatutos e programas. A esse respeito, há obrigatoriedade de registro dos estatutos perante o TSE, sendo isso requisito para que o partido possa adquirir capacidade eleitoral e participar das eleições (artigo $9^{\circ}$ da Lei 9.096/95 e artigo $4^{\circ}$ da Lei 9.504/97; CONEGLIAN, 2014, p. 34-37). Com o registro, o partido político tem resguardada a sua denominação, sigla e símbolos.

Segundo o artigo 10 da Lei 9.096/95, quaisquer mudanças programáticas ou estatutárias devem ser registradas de acordo com a lei civil e no TSE. Tudo porque ali estará a alma das agremiações: seus ideais, objetivos políticos, estrutura interna, organização e funcionamento.

Neste sentido, cabe transcrever os artigos 14 e 15 da Lei 9.096/95, que dispõem:

Art. 14. Observadas as disposições constitucionais e as desta Lei, o partido é livre para fixar, em seu programa, seus objetivos políticos e para estabelecer, em seu estatuto, a sua estrutura interna, organização e funcionamento.

Art. 15. O Estatuto do partido deve conter, entre outras, normas sobre:

I - nome, denominação abreviada e o estabelecimento da sede no território nacional; (Redação dada pela Lei ${ }^{\circ} 13.877$, de 2019)

II - filiação e desligamento de seus membros;

III - direitos e deveres dos filiados;

IV - modo como se organiza e administra, com a definição de sua estrutura geral e identificação, composição e competências dos órgãos partidários nos níveis municipal, estadual e nacional, duração dos mandatos e processo de eleição dos seus membros;

V - fidelidade e disciplina partidárias, processo para apuração das infrações e aplicação das penalidades, assegurado amplo direito de defesa;

VI - condições e forma de escolha de seus candidatos a cargos e funções eletivas;

VII - finanças e contabilidade, estabelecendo, inclusive, normas que os habilitem a apurar as quantias que os seus candidatos possam despender com a própria eleição, que fixem os limites das contribuições dos filiados e definam as diversas fontes de receita do partido, além daquelas previstas nesta Lei;

VIII - critérios de distribuição dos recursos do Fundo Partidário entre os órgãos de nível municipal, estadual e nacional que compõem o partido;

IX - procedimento de reforma do programa e do estatuto. 
Os estatutos são os instrumentos pelos quais o partido político dá publicidade às suas bandeiras e símbolos, divulgando-os na sociedade como sendo seus. Ideais esses nos quais se pautam os eleitores, que, por isso, votam.

Aqui há a própria ideia de identidade do eleitor - que leva ao voto - e, por conseguinte, representatividade.

\section{CRISE DE REPRESENTATIVIDADE NO CONTROLE ABSTRATO?}

Contudo, constatou-se que os partidos políticos judicializam no STF, na maioria das vezes, temas que não encontram correspondência com seus ideais partidários (SOBRAL NETO, 2014; MELO e GOMES NETO, 2015). A incompatibilidade entre as ADIs propostas e os estatutos é quase uma regra, tamanha a periodicidade com que ocorre o evento. As causas trazidas ao Judiciário através do controle abstrato não estão em consonância com a função representativa desses mandatários públicos. Esses atores estão orientados pelos seus interesses, não por uma ética republicana ou democrática.

Melo e Gomes Neto (2015) realizaram pesquisa empírica a fim de aferir a compatibilidade entre as ADIs propostas por partidos pequenos de direita e de centro-direita e os seus respectivos ideais partidários. Foram coletadas todas as ações do período de 1988 a 2014, disponíveis no site do Supremo Tribunal Federal. Para identificar partidos pequenos de direita, recorreram a estudos de Gabriela Tarouco (2013) e criaram uma tabela qualitativaquantitativa, com o intuito de medir o grau ideológico de cada partido. Como resultado, chegaram a estes partidos minoritários de direita: PRB, PHS, PSL, PTC, PSC e PTR (atual PRTB).

Tendo analisado as petições iniciais de cada ação direta, agruparam em categorias os seus temas. Processo penal, questões constitucionais, direitos fundamentais, questões previdenciárias, de competência, administrativas, licitações, servidores públicos e Direito Tributário foram assim quantificadas: 
Gráfico 1. Temas das ações diretas de inconstitucionalidade propostas por partidos pequenos de direita e de centro-direita

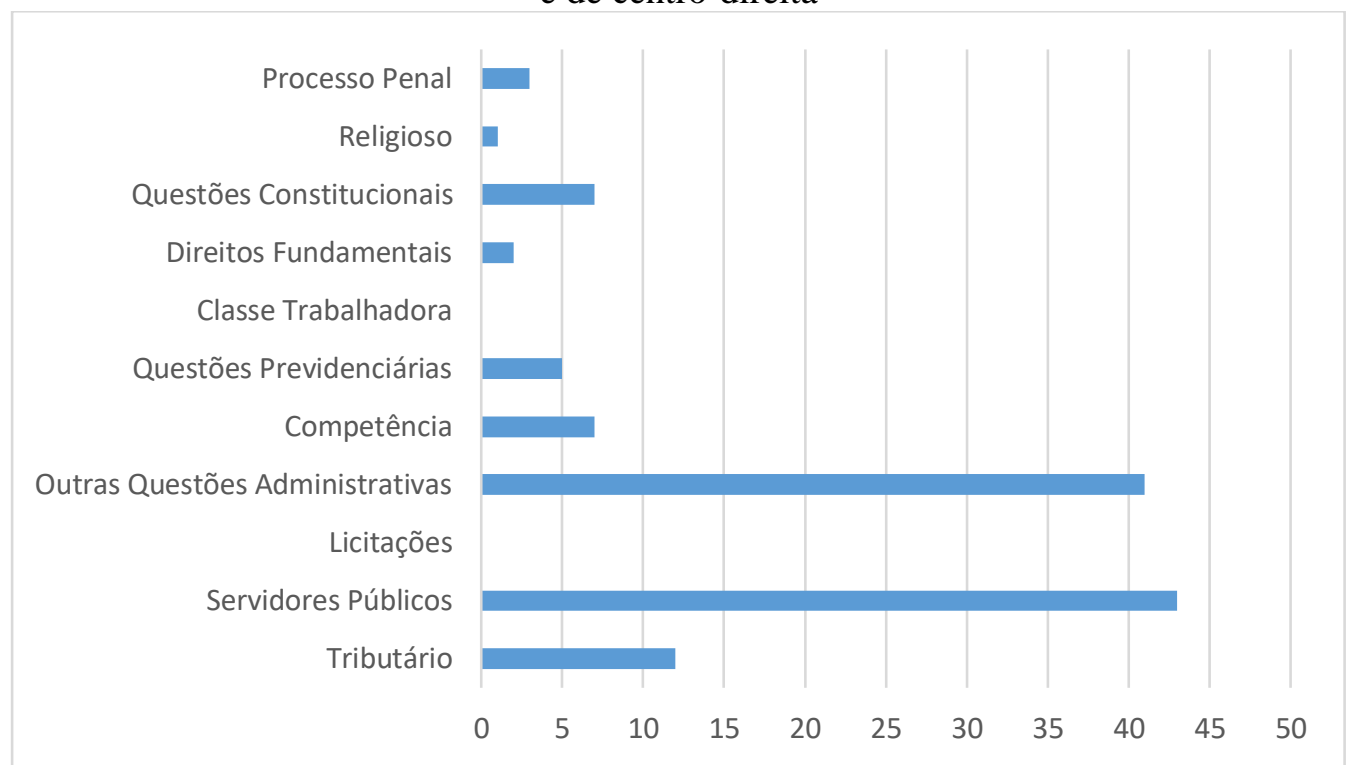

Fonte: (MELO e GOMES NETO, 2015)

Questões administrativas e ações sobre servidores públicos e temas de Direito Tributário foram as categorias que mais se destacaram. Juntas, somam 96 ações ajuizadas, num universo de 111 ADIs - o equivalente a $86 \%$ do total.

No que se refere ao Partido Social Liberal (PSL), por exemplo, 85 ações foram ajuizadas apenas por esse partido. É a agremiação que mais demandou o Judiciário, dentro do universo analisado. Dessas 85 ações, notou-se que 16 versaram sobre o Ministério Público: cinco delas, sobre a competência do órgão, abordando especialmente o poder de investigar (função de polícia judiciária e apuração de infrações penais); mas a grande maioria tratou de tópicos como vedações, prerrogativas, reversão e afastamento dos membros ministeriais, nomeação, atribuições, vencimentos e destituição do Procurador Geral de Justiça dos Estados - por esse motivo, classificadas como questões administrativas.

Quando da análise da correspondência entre as ADIs e os estatutos, verificou-se:

Gráfico 2. Análise da compatibilidade entre ideais partidários e temas das ADIs (ADINs) propostas por partidos pequenos de direita e de centro-direita 


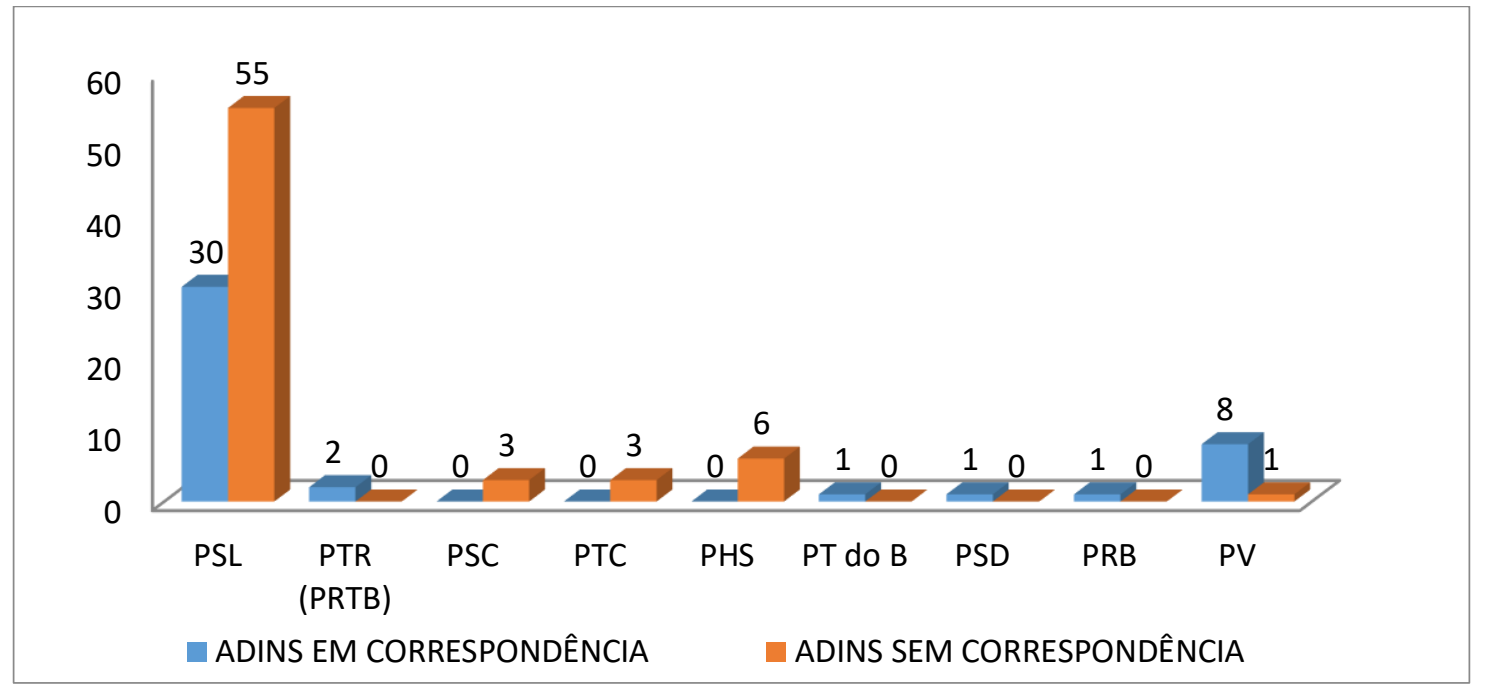

Fonte: (MELO; GOMES NETO, 2015)

Como se pode constatar, há uma grande tendência para a falta de compatibilidade entre a prática (as ações propostas) e a teoria (os ideais partidários defendidos nos estatutos). Das 85 ações ajuizadas pelo Partido Social Liberal (PSL), por exemplo, 50 não guardaram correspondência com o que a agremiação prega.

Sobral Neto (2014), por sua vez, também realizou estudo empírico, mas desta vez a fim de observar a compatibilidade entre as ADIs propostas por partidos pequenos de esquerda e de centro-esquerda e os seus respectivos ideais partidários. Por meio de critério análogo ao de Melo e Gomes Neto (2015), Sobral Neto chegou aos seguintes partidos de esquerda: PPS, PC do B, PSB, PSOL, PMN, PST (PL). 
Gráfico 2. Análise da compatibilidade entre ideais partidários e temas das ADIs (ADINs) propostas por partidos pequenos de esquerda e de centro-esquerda

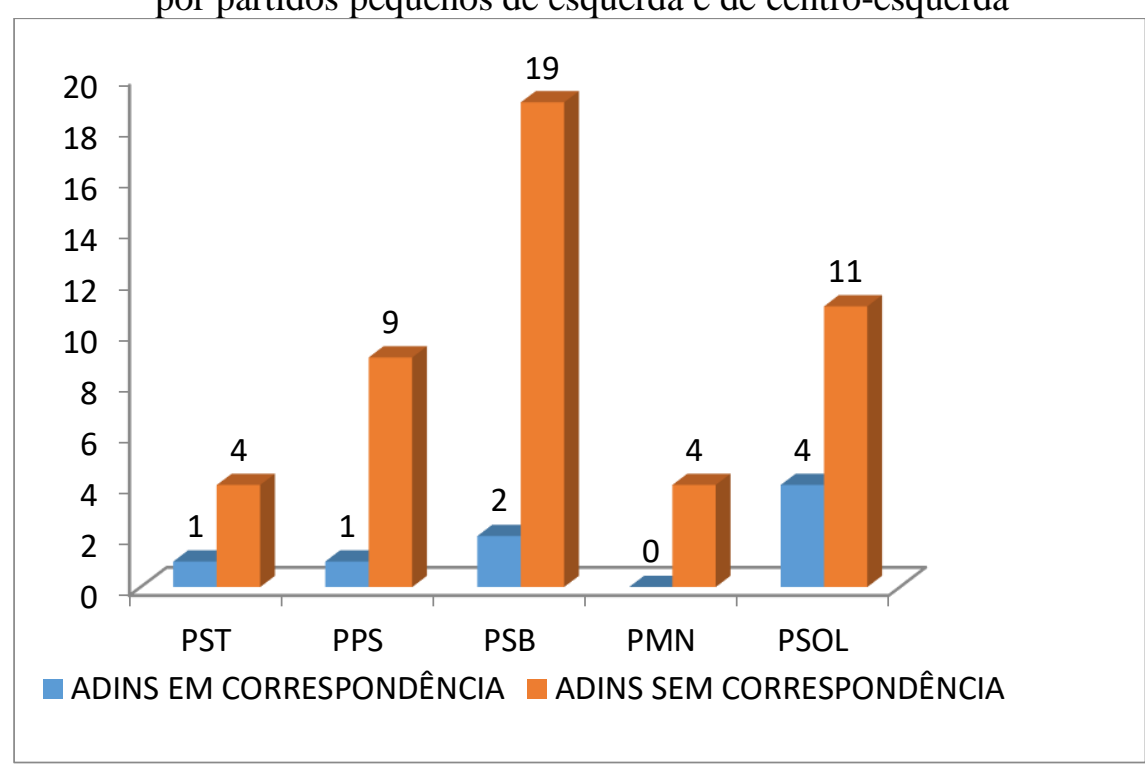

Fonte: (SOBRAL NETO, 2014)

Desse modo, os resultados obtidos por Sobral Neto referentes à compatibilidade entre as ADIs e os estatutos foram no sentido de confirmar a hipótese de os partidos políticos, ao acionarem o judiciário, não estarem de fato atuando como agentes representativos. As matérias submetidas ao STF ao longo desses anos não correspondem, na sua grande maioria, diretamente ao que está disposto e defendido nos respectivos estatutos partidários. Por conseguinte, se esses estatutos veiculam os ideais partidários, os partidos então não cumprem com o que defendem e afastam-se da sua função representativa no momento em que acionam o controle abstrato e, consequentemente, atuam na jurisdição constitucional.

A ideia de democratizar a jurisdição constitucional, por meio da ampliação do rol dos legitimados ativos promovida pela constituinte de 1988, não está cumprindo por inteiro a sua finalidade: garantir aos atores uma via para defender os interesses dos seus representados. Ocorre que, na prática, determinados atores atuam no controle de constitucionalidade a fim de satisfazer outros interesses, antes de defender aqueles que deveriam ser seu objeto principal de ocupação. 


\section{OS PARTIDOS NO SUPREMO: UMA ANÁLISE EXPLORATÓRIA DE AÇÕES PROPOSTAS PELAS AGREMIAÇÕES}

Primeiramente, cabe destacar que o controle concentrado pode ser desvirtuado em pelo menos duas circunstâncias: a) no caso de se submeter à Corte questões que não deveriam ser próprias do controle concentrado (por exemplo, a demanda de um particular, visto tratar-se de processo objetivo, a partir de uma lei abstrata); b) nas hipóteses de ajuizar perante a Corte questões alheias aos interesses representados e, por conseguinte, estranhas ao fim último da existência dos próprios atores.

Nesta segunda situação, em especial, verifica-se um desvio na função primária das legendas partidárias, qual seja, a função representativa, que também é a razão da própria ampliação do rol de legitimados ativos e, por conseguinte, do acesso ao controle concentrado (CARVALHO, 2008). Isso porque, se o legislador constituinte promoveu o acesso dos partidos políticos ao controle concentrado, o fez de modo a ampliar o debate sobre os interesses supostamente representados, bem como a oferecer aos partidos de oposição um fértil campo para a exposição contínua de ideias derrotadas na esfera do parlamento (TAYLOR e DA ROS, 2008).

Aqui serão discutidos casos em que o mau uso do mecanismo de retificação do tipo abstrato pode ser classificado nessa segunda categoria.

A discussão cingir-se-á a cinco casos, porém vale lembrar que, conforme Sobral Neto (2014) e Melo e Gomes Neto (2015), são rotineiros os casos de incongruência entre os temas que os partidos políticos levam ao Supremo Tribunal Federal e os respectivos programas e estatutos partidários. Sobral Neto e Melo e Gomes Neto chegaram a resultados que apontam desvios de finalidade nas ordens de 85,45\% e 61,26\%, respectivamente, grandezas essas que demonstram o quanto é comum um partido político litigar no Supremo Tribunal Federal por interesses que nada tem a ver com os ideais que expõem nos seus estatutos e, por conseguinte, com o seu papel representativo. A prática tumultua a revisão judicial e prejudica a representatividade das agremiações (e por que não dizer também prejudica a credibilidade?), bem como interfere na própria agenda do Tribunal, que se vê apreciando questões não 
representativas em detrimento de relevantes litígios submetidos ao controle concentrado, os quais aguardam julgamento.

Para efeitos deste artigo, será feita a análise comparativa dos casos, confrontando o objeto das ações com o conteúdo dos estatutos das respectivas legendas partidárias, de modo a indicar por que naquelas ações do controle concentrado haveria um desvio de finalidade da revisão judicial pela não correspondência com os interesses políticos supostamente representados pelo partido.

Como primeiro caso a ser analisado, elegeu-se a ADI 3952. Ajuizada pelo Partido Trabalhista Cristão (PTC) em 2007, a ADI 3952 tinha por fim impugnar o art. $1^{\circ}$ da Lei 9.822, de 23 de agosto de 1999, que alterou dispositivos do Decreto-Lei no 1.593, de 21 de dezembro de 1977. Tem-se como plano de fundo questão de Direito Tributário, pois foram tratadas regras sobre o Imposto sobre Produto Industrializado (IPI), obrigação tributária cujo descumprimento poderia cancelar sumariamente o registro especial, necessário a estabelecimentos que fabriquem ou importem cigarros.

Ocorre que o estatuto do PTC vigente naquele ano de 2007 dispõe como ideais partidários apenas:

\begin{abstract}
ARTIGO $2^{\circ}$ - A defesa das instituições políticas, livres e democráticas; a defesa intransigente das liberdades individuais, o combate à impunidade e a injustiça, a pregação incansável da fraternidade, do amor e dos valores Cristãos, se constituirá na linha de Ação do Partido Trabalhista Cristão. (PARTIDO TRABALHISTA CRISTÃO, 2007)
\end{abstract}

Como é possível perceber, não há qualquer menção ao objeto da ADI citada, que se limita exclusivamente a discutir questão tributária de interesse restrito à indústria do tabaco. A defesa do desempenho dessa atividade econômica não encontra guarida nos ideais partidários anunciados pelo estatuto, quais sejam, "defesa das instituições políticas, livres e democráticas; a defesa intransigente das liberdades individuais, o combate à impunidade e a injustiça, a pregação incansável da fraternidade, do amor e dos valores Cristãos”. Portanto, quando confrontado o objeto desta ação direta de inconstitucionalidade com o que dispõe o estatuto do PTC, conclui-se não haver compatibilidade entre ambos.

O segundo caso a ser analisado é o da ADI 4299, proposta pelo Partido Humanista da Solidariedade (PHS) em 2009. A ação direta objetivou impugnar Resoluções do Conselho da 
Magistratura de Santa Catarina e Resoluções do Tribunal de Justiça daquele mesmo Estado, que regulamentavam o ingresso e a remoção na atividade notarial e de registro catarinense e promoviam a reorganização desses serviços. Tal questão controversa traduz interesse corporativo dos ocupantes de cargos notariais ou daqueles que pretendam fazer concurso público para tais funções.

Ao comparar o tema da referida ação com o estatuto do citado partido, verificou-se a não correspondência entre ambos. Cabe registrar que o PHS renovou, em seu estatuto de 2009, os ideais partidários contidos no estatuto de 1997, quando ainda respondia pela nomenclatura de Partido da Solidariedade Nacional (PSN):

\begin{abstract}
ARTIGO $3^{\circ}$ - Os seis princípios básicos sobre os quais está alicerçado o pensamento do PHS são: I - a PESSOA HUMANA, criada por Deus e considerada nas suas inalienáveis dignidade e liberdade, é a protagonista, o centro e o propósito de toda ação política; II - o DESTINO UNIVERSAL DOS BENS DA TERRA faz pesar sobre toda propriedade uma hipoteca social; III - o BEM COMUM, crivo sob o qual devem ser avaliadas as mais diversas situações e conjunto das condições concretas que permitem a todos os membros de uma comunidade atingir níveis de vida à altura da dignidade da pessoa humana, é o sentido essencial do Estado; IV - a SUBSIDIARIEDADE, que manda delegar a instância mais próxima da base social todo o poder decisório que esteja em condições de exercer, é a chave da participação e assegura aos interessados o direito de manifestar-se a respeito das matérias que lhes digam respeito; $\mathrm{V}$ - a PRIMAZIA DO TRABALHO (pessoas) SOBRE O CAPITAL (bens materiais) rege a organização da economia; e IV - a SOLIDARIEDADE plena requer a presença de três fatores fundamentais: a Justiça (aliada à Legitimidade), a Liberdade e o Amor fraterno, para assegurar eficácia e perenidade a toda organização social. (PARTIDO HUMANISTA DA SOLIDARIEDADE, 1997)
\end{abstract}

Assim sendo, não há ideal partidário no estatuto da agremiação que ampare o interesse corporativo dos ocupantes de cargos notariais ou daqueles que pretendam fazer concurso público para tais funções. A pessoa humana, o destino universal dos bens da terra, o bem comum, a subsidiariedade, a primazia do trabalho sobre o capital e a solidariedade não justificam a discussão quanto à regulamentação do ingresso e da remoção na atividade notarial e de registro catarinense, tampouco a reorganização desses serviços. Logo, não há correspondência com o estatuto, por não tratar das questões gerais nele consignadas.

Como outro caso a ser analisado, o Partido Progressista (PP) ajuizou, em 2009, a ADPF 172, a fim de impugnar a decisão da $16^{\mathrm{a}}$ Vara Federal do Rio de Janeiro, que concedeu a guarda do menor Sean Goldman ao pai biológico, um estadunidense, com a determinação de que a criança voltasse aos Estados Unidos de forma imediata e ordem para que fosse apresentado ao 
Consulado em 48 horas. No caso, após a morte da mãe de Sean, a sua família materna, brasileira, e o seu padrasto, advogado e também brasileiro, travaram conflito judicial com o pai biológico, David Goldman, cidadão dos Estados Unidos. O litígio versava sobre a guarda do menor. Antes do prazo estabelecido pelo magistrado de primeira instância, contudo, o ministro Marco Aurélio concedeu liminar na ADPF 172 para manter o menino no Brasil.

O estatuto do PP, à época, dispunha apenas o seguinte:

CAPÍTULO I DO PARTIDO E SEUS OBJETIVOS Art. $1^{\circ}$, O Partido Progressista $\mathrm{PP}$, que adota o número 11 (onze), pessoa jurídica de direito privado, com sede e foro na capital da República, reger-se-á por este Estatuto e orientará sua ação pelo Programa aprovado em Convenção Nacional. Parágrafo único. O Partido será integrado pelos filiados que, pelas fusões e incorporações lhe deram origem, e por todos os cidadãos que nele se inscreveram ou vierem a se inscrever, aceitando seu Programa e seus princípios programáticos, e exercerá suas atividades nos limites da autonomia política do Estado Democrático de Direito. (PARTIDO PROGRESSISTA, 2009)

Nota-se que o estatuto da época era insuficiente no seu papel de expor os objetivos e ideais partidários. Buscou-se, portanto, o que dispunha o programa partidário:

\section{Programa Partidário}

Os progressistas na sua já longa história partidária, permanentemente empenhados em contribuir para a construção de um País moderno e de uma sociedade baseada na dignidade humana, e que seja justa, livre, democrática, pluralista, solidária e participativa, fundamentam a sua ação programática nos seguintes valores, princípios e crenças políticas:

I - busca continua do ideário democrático e dos objetivos nacionalistas de seus fundadores em elevar a Nação brasileira a um patamar de desenvolvimento econômico-social que possibilite à sua população uma vida digna e com igualdade de oportunidades para todos os cidadãos;

II - liberdade de culto religioso, garantia da inviolabilidade da privacidade, direito ao trabalho digno, ao salário justo, à moradia, à educação, à saúde, à alimentação, ao lazer, à segurança, bem como o exercício de uma imprensa livre e responsável e à preservação do meio-ambiente;

III - intangibilidade da Federação, harmonia dos poderes e crescente autonomia dos Estados e Municípios;

IV - consecução de um sistema econômico livre, que favoreça a prática das regras de mercado, mas que tenha como objetivo maior o bem-estar dos brasileiros e a eliminação das desigualdades sociais;

V - ação do Estado no campo econômico que leve em conta valores sociais como a criação e a distribuição de riquezas para todos com geração de empregos, renda, poupança, consumo e funcionamento de efetiva economia social de mercado; e,

VI - permanente adaptação para o processo de mudança continuada da sociedade, da economia brasileira e das responsabilidades dos entes federados.

Seguindo esses valores, princípios e crenças políticas, o PP orienta a sua ação programática com a convicção de que para a consolidação do regime democrático no País é necessário a existência de partidos políticos organizados e bem estruturados que garantam a legitimidade e a proporcionalidade da representação política, alicerçada no livre exercício, independente e consciente do voto secreto, na 
periodicidade dos mandatos, na rotatividade dos partidos no poder, respeitada a pluralidade doutrinária ideológica. (PARTIDO PROGRESSISTA, 2018)

Como é possível perceber, tampouco o programa partidário do PP abriga fundamento para que o partido defenda a guarda de um menor. Um debate nesse sentido por si só já seria de causar estranheza e polêmica, uma vez que se trata de uma impugnação a decisão judicial em um litígio que envolve interesses particulares, não coletivos. Assim sendo, haveria um debate em torno da própria natureza da demanda submetida (a guarda específica de um menor), visto que o controle de constitucionalidade pressupõe uma relevância da matéria para uma coletividade, ou seja, repercussão geral. Some-se a esse debate o fato de a própria contenda não guardar correspondência com os ideais partidários hasteados no estatuto e no programa.

Como um quarto caso a ser analisado, temos a ADI 1666, proposta pelo Partido Democrático Trabalhista (PDT) em 1997, na qual foi questionada a constitucionalidade da Lei $\mathrm{n}^{\circ}$ 10.847/96. Alegou-se vício de competência para editar tal lei, cujo objetivo foi o de criar o departamento Estadual de Trânsito/DETRAN/RS. Todavia, essa questão não corresponde a um interesse estampado no estatuto do aludido partido político na época em que a ação foi ajuizada:

Art. $1^{\circ}$ - O Partido Democrático Trabalhista - PDT - é uma organização política da Nação Brasileira para a defesa de seus interesses, de seu patrimônio, de sua identidade e de sua integridade, e tem como objetivos principais lutar, sob a inspiração do nacionalismo e do trabalhismo, pela soberania e pelo desenvolvimento do Brasil, pela dignificação do povo brasileiro e pelos direitos e conquistas do trabalho e do conhecimento, fontes originárias de todos os bens e riquezas, visando à construção de uma sociedade democrática e socialista. $\S 1^{\circ}$ - O Partido, como instituição, e seus filiados individualmente atuarão por métodos democráticos e pacíficos, ainda que, quando necessário, com indignação, rigor e energia, essencialmente na linha dos seguintes compromissos básicos: · com a Nação e sua história de lutas pelo domínio de seu território e de suas riquezas e com o projeto de seu desenvolvimento pleno, capaz de afirmar sua soberania e independência. • educação, causa de salvação nacional, prioridade das prioridades: alimentar, acolher e assistir a todas as crianças do País, desde o ventre materno; educá-las e escolarizá-las em tempo integral, sem qualquer tipo de discriminação; · trabalho digno e assistência à saúde para todos os brasileiros; · salário justo para todos os trabalhadores, que têm o direito de serem os principais beneficiários dos frutos de seu trabalho; - defesa do patrimônio público e das riquezas nacionais. Estancar espoliação colonial a que está submetido o País e reverter às perdas internacionais da nossa economia. Resgate do patrimônio e reparação dos prejuízos e danos causados pelas concessões a grupos econômicos e pelas privatizações lesivas ao interesse público; · racionalizar e democratizar o Estado nacional brasileiro e a Federação, colocando-os a serviço dos interesses e direitos do nosso povo; - reorganizar a agricultura em torno da pequena e média propriedade e realizar a reforma agrária, aumentar a produção de tal modo a que não faltem alimentos a nenhuma família brasileira; · lutar pela causa da mulher, do negro, do índio, dos jovens e dos idosos, sem qualquer forma de discriminação; · reformular o sistema financeiro para torná-lo instrumento de desenvolvimento nacional; · defender a dignidade da função pública, sob a inspiração da moral e da ética, com o objetivo de servir ao cidadão e prestigiar o servidor; · em defesa da natureza brasileira e por 
um meio ambiente sadio para a preservação da base biológica e do desenvolvimento auto-sustentado do nosso País; (PARTIDO DEMOCRÁTICO TRABALHISTA, 1996)

A questão discutida na ADI 1666 foi, portanto, a natureza da vistoria das condições de segurança dos veículos (se seria atividade decorrente do poder de política da administração ou prestação de serviço público), a fim de que, com a resolução desse impasse, se soubesse de quem seria a competência para regulá-la ou realizar o contrato de concessão. Contudo, ao confrontar o tema da ação direta com os ideais partidários descritos no estatuto da agremiação política, nota-se a incompatibilidade entre ambos, por faltar ideal partidário apto a albergar a pretensão jurídica.

Por fim, como último caso a ser discutido aqui, tem-se a ADI 5282, proposta em março de 2015 pelo PT. A ação direta discutiu a constitucionalidade de artigos que introduziram novas regras para a cobrança do IPVA no estado do Paraná durante o ano de 2015, mais especificamente alterando as datas de ocorrência do fato gerador e de vencimento do referido imposto naquele ano, após ter majorado a alíquota do tributo.

Por sua vez, o estatuto do PT em vigor durante o ano em que foi ajuizada a ADI assim dispõe:

Art. 19. O Partido dos Trabalhadores (PT) é uma associação voluntária de cidadãos e cidadãs que se propõem a lutar por democracia, pluralidade, solidariedade, transformações políticas, sociais, institucionais, econômicas, jurídicas e culturais, destinadas a eliminar a exploração, a dominação, a opressão, a desigualdade, a injustiça e a miséria, com o objetivo de construir o socialismo democrático. (PARTIDO DOS TRABALHADORES, 2014)

Como é possível perceber, a questão tributária não encontra amparo direto em nenhum dos ideais partidários citados no estatuto da agremiação política petista. Não há qualquer menção ao objeto da ADI citada, que se limita exclusivamente a discutir questão tributária de interesse adstrito aos proprietários de veículos.

O resultado desses cinco exemplos e das pesquisas empíricas oferecidas por Sobral Neto (2014) e Melo e Gomes Neto (2015) apontam para a existência do fenômeno da não compatibilidade entre os ideais partidários e as demandas judiciais das agremiações políticas. Por conseguinte, confirma-se também uma outra vertente da crise de representatividade dos partidos políticos: o Estado encontra-se cada vez mais afastado de sua função precípua - 
representar - para assumir, no lugar dela, função cada vez mais burocrática, olvidando-se do eleitorado (MAIR, 2003). Os estatutos, uma vez não observados na atividade prática dos partidos, parecem estar a meramente cumprir um requisito formal, exigido tanto pelo art. 17 da Constituição Federal quanto pelo Tribunal Superior Eleitoral (TSE) para a constituição da pessoa jurídica, nada mais.

\section{CONCLUSÕES: PERTINÊNCIA TEMÁTICA PARA OS PARTIDOS POLÍTICOS}

A função primeira das agremiações políticos é a de representação. No entanto, no Brasil, esses partidos comumente judicializam questões não compatíveis com os seus estatutos e, por conseguinte, alheias aos seus ideais partidários e ao que é esperado pelos eleitores que neles votam. Assim sendo, os partidos políticos estão servindo para que interesses não legitimados tenham acesso ao controle concentrado.

O problema da crise representativa não atinge, portanto, apenas a esfera política, mas também o Direito - como naturalmente haveria de ser, pois os sistemas, embora independentes, são cognitivamente abertos, pelo que devem ser reciprocamente considerados. Eles detêm uma interface: a Constituição, a qual autoriza o fenômeno da judicialização da política. Diante da crise de representatividade em que se inserem, mecanismos que visem a responsabilidade dessas instituições se fazem necessários. Imperioso garantir a função representativa dos mandatários públicos, para fazer-lhes gozar de maior crédito perante a sociedade, que, pelo desenho institucional, não se reconhece mais nos seus representantes.

O fenômeno da judicialização da política é importante para a democracia, pois traz consigo a ideia de vigilância acerca do funcionamento da ordem jurídica e da sociedade, bem como contribui para maior acesso ao debate jurisdicional. Contudo, o modo como encontra-se desenhado este fenômeno no ordenamento brasileiro, com um amplo direito de acesso à Corte, atribui ao Tribunal uma sobrecarga de trabalho, fora aquela que invariavelmente a sua natureza já lhe atribui (o STF funciona tanto como órgão de cúpula como Corte Constitucional). 
No caso dos partidos políticos, então legitimados universais, a inexistência de um filtro para propositura não apenas coloca em risco a ordem e segurança jurídicas, mas permite, no campo jurídico, que eles atuem com os mesmos vícios da esfera política: não obedecendo ao seu papel primeiro de representação. Por isso, propõe-se a relevância temática como requisito para o interesse de agir.

A pertinência temática serve como demonstrativo do interesse de agir. Deve-se comprovar relevância da matéria tema da ação direta para as atividades institucionais, um nexo entre ambas. Havendo uma exigência desse porte, evitar-se-ia a propositura incompatível com os ideais partidários.

Os partidos políticos estão em primeiro lugar no ranking dos números de ADIs ajuizadas. A demanda é farta. Além de responsável por causar um grande trabalho ao STF, cabe afirmar, é o único dos atores políticos com ações na Corte que não deve obedecer ao critério da relevância temática, gozando, pelo desenho do mecanismo de controle concentrado, de legitimidade ampla e, por que não dizer, irrestrita.

Não se está aqui a exigir que os representantes consultem previamente o eleitorado sobre como devem conduzir a coisa pública; não se pretende o retorno ao mandato imperativo. Entende-se que ele não é mais adequado à complexa sociedade contemporânea. Ao exigir a pertinência temática, requer-se razões pelas quais o partido está assim a agir, a ajuizar as ADIs. Pretende-se que a agremiação informe e justifique por que atua, para tornar possível o juízo dos eleitores sobre suas ações e posterior punição/compensação - a accountability.

O Judiciário, pelo controle de constitucionalidade, é ator político e proporciona aos partidos uma nova arena para os debates. Funciona como espaço alternativo, o qual foi dado pelo constituinte de 1988 sobretudo como poder dado às minorias e oposições para resguardarem as regras do jogo. No entanto, está a justiça constitucional a servir a outros interesses, que nem ela sabe, e não correspondem aos de conhecimento do eleitor.

A proposta é tocar a responsabilidade, dando-lhe mais mecanismos para que se consiga uma melhor qualidade de democracia. Os partidos não se definem nos estatutos e poucos são aqueles que possuem um programa acessível aos cidadãos. Logo, a caracterização fica comprometida, tornando difícil o reconhecimento da identidade do partido e, por conseguinte, 
a escolha do candidato; aumenta a descrença e o abismo entre política e cidadão. Não é que não vá existir cidadão que não queira se comprometer com a política; eles existirão. Contudo, há de se manter um vínculo e arcabouço propício à cobrança de justificativa e informação, a fim de mais perto se chegar do ideal de democracia representativa.

O filtro não solucionará, como evidente, o problema da crise de representatividade por completo, pois ela possui raízes profundas e ultrapassa, como dito, a esfera jurídica. A accountability deve ser pensada também em níveis mais densos. Porém, ao menos diante da justiça constitucional, ter-se-ia mecanismo capaz de impor uma conformidade entre bandeiras hasteadas pelos partidos e a sua atividade prática na órbita jurídica. Não faz sentido conferirlhes uma prerrogativa justificada pelo seu relevante papel na democracia quando, a bem da verdade, tais atores políticos não atuam orientados por ética republicana ou democrática; quando a classe age unicamente por seus interesses, olvidando dos eleitores.

\section{REFERÊNCIAS}

BRASIL. Lei n ${ }^{\circ}$ 9.096, de 19 de setembro de 1995. Dispõe sobre partidos políticos, regulamenta os arts. 17 e 14, § 3º, inciso V, da Constituição Federal. Diário Oficial da União. Brasília, DF, 20 set. 1995. Disponível em: http://www.planalto.gov.br/ccivil_03/leis/19096.htm. Acesso em: 10 dez. 2020.

BRASIL. Lei n ${ }^{\circ}$ 9.504, de 30 de setembro de 1997. Estabelece normas para as eleições. Diário Oficial da União. Brasília, DF, 01 out. 1997. Disponível em: http://www.planalto.gov.br/ccivil_03/LEIS/L9504.htm. Acesso em: 10 dez. 2020.

BRASIL. Supremo Tribunal Federal. ADI 779, Relator(a): Min. CELSO DE MELLO, julgada em 08/10/1992. Diário de Justiça da União. Brasília, DF, 11 mar. 1994. Disponível em: http://redir.stf.jus.br/paginadorpub/paginador.jsp?docTP=AC\&docID=363408. Acesso em: 15 dez. 2020.

BRASIL. Supremo Tribunal Federal. ADI 1.528, Relator(a): Min. ELLEN GRACIE, julgada em 24/05/2000. Diário de Justiça da União. Brasília, DF, 23 ago. 2002. Disponível em: http://redir.stf.jus.br/paginadorpub/paginador.jsp?docTP=AC\&docID=962. Acesso em: 15 dez. 2020.

BRASIL. Supremo Tribunal Federal. ADI 1666, Relator(a): Min. CARLOS VELLOSO, julgada em 16/06/1999. Diário de Justiça da União. Brasília, DF, 22 fev. 2004. Disponível em: 
http://redir.stf.jus.br/paginadorpub/paginador.jsp?docTP=AC\&docID=347200. Acesso em: 15 dez. 2020.

BRASIL. Supremo Tribunal Federal. ADI 3952, Relator(a): Min. JOAQUIM BARBOSA. Diário de Justiça da União. Brasília, DF, 22 set. 2008. Disponível em: http://portal.stf.jus.br/processos/detalhe.asp?incidente=2556011. Acesso em: 15 dez. 2020.

BRASIL. Supremo Tribunal Federal. ADI 4299 SC, Relator(a): Min. RICARDO LEWANDOWSKI, julgada em 07/10/2009. Diário de Justiça da União. Brasília, DF, 15 out. 2009. Disponível em: http://portal.stf.jus.br/processos/detalhe.asp?incidente=3756217. Acesso em 15 dez. 2020.

BRASIL. Supremo Tribunal Federal. ADI 5282 PR, Relator(a): Min. MARCO AURÉLIO. Disponível em: http://portal.stf.jus.br/processos/detalhe.asp?incidente=4741447. Acesso em: 15 dez. 2020.

BRASIL. Supremo Tribunal Federal. ADPF 172 RJ, Relator(a): Min. MARCO AURÉLIO, julgada em 09/06/2009. Diário de Justiça da União. Brasília, DF, 17 jun. 2009. Disponível em: http://redir.stf.jus.br/paginadorpub/paginador.jsp?docTP=AC\&docID=601123. Acesso em: 15 dez. 2020.

BURKE, Edmund. Speech to the Electors of Bristol. Revista de Sociologia e Política, v. 20, n. 44, p. 97-101, 2012.

CARVALHO, Ernani Rodrigues de. Dimensão política do acesso à justiça: aspectos da revisão judicial. In: GOMES NETO, José Mário Wanderley. Dimensões do acesso à justiça. Salvador, JusPodivm, 2008, p. 41-50.

CARVALHO, Ernani Rodrigues de; SANTOS, Manuel Leonardo; GOMES NETO, José Mário Wanderley. Interactions between the Brazilian Supreme Court and the National Industry Union in Corporative Political Disputes. In: 22nd World Congress of Political Science (IPSA) Madrid. Montreal: International Political Science Association (IPSA), 2011.

CONEGLIAN, Olivar. Propaganda eleitoral: Eleições 2014. Curitiba: Juruá, 2014.

CRETELLA JÚNIOR, José. Comentários à Constituição brasileira de 1988. Rio de Janeiro: Forense Universitária, 1989.

DA SILVA, José Afonso. Curso de Direito Constitucional Positivo. 37. ed., rev. atual. São Paulo: Malheiros, 2014.

DAHL, Robert A.. Sobre a democracia. Tradução de Beatriz Sidou. Brasília: Editora UNB, 2001.

DALLARI, Dalmo. Elementos da Teoria Geral do Estado. 29. ed. São Paulo: Saraiva, 2010.

LIMA, Flávia Danielle Santiago.; GOMES NETO, José Mário Wanderley. Autocontenção à brasileira? Uma taxonomia dos argumentos jurídicos (e estratégias políticas?) explicativo(a)s 
do comportamento do STF nas relações com os poderes majoritários. Revista de Investigações Constitucionais, v. 5, p. 221-247, 2018.

LUCON, Paulo Henrique dos Santos; VIGLIAR, José Marcelo Menezes. Código Eleitoral Interpretado. São Paulo: Atlas., 2011.

MAIR, Peter. Os partidos políticos e a democracia. Análise Social, v. XXXVIII, p. 277-293, 2003.

MELO, Gabriela Perrelli de; GOMES NETO, José Mário Wanderley. Liberais na Corte: judicialização de questões políticas no Supremo Tribunal Federal por partidos políticos minoritários de direita. In: XXIV Encontro Nacional do CONPEDI - UFS. Florianópolis: CONPEDI, 2015.

NUNES JÚNIOR, Amandino Teixeira. Ativismo judicial no Brasil: o caso da fidelidade partidária. Revista de Informação Legislativa, ano 51, n. 201, p. 97-128, 2014.

PARTIDO DOS TRABALHADORES. Estatuto. Disponível em: <http://www.justicaeleitoral.jus.br/arquivos/tse-estatuto-do-pt-deferido-em-5-junho-2014>. Acesso em: 15 de outubro de 2018.

PARTIDO HUMANISTA DA SOLIDARIEDADE. Estatuto. Disponível em: <http://www.justicaeleitoral.jus.br/arquivos/estatuto-do-partido-humanista-da-solidariedadede-24-08-1997>. Acesso em: 12 de novembro de 2016.

PARTIDO PROGRESSISTA. Estatuto. Disponível em: <http://www.justicaeleitoral.jus.br/arquivos/estatuto-do-partido-progressista-de-2-4.2009>. Acesso em: 28 de julho de 2018.

PARTIDO PROGRESSISTA. Programa Partidário. Disponível em: <http://www.pp.org.br/2056/Documentos/ProgramaPartidario_261600/>. Acesso em: 28 de julho de 2018.

PARTIDO TRABALHISTA CRISTÃO. Estatuto. Disponível em: <http://www.justicaeleitoral.jus.br/arquivos/tse-estatuto-do-partido-ptc-de-24-3-2007resolucao.2007>. Acesso em: 12 de novembro de 2016.

PARTIDO DEMOCRÁTICO TRABALHISTA. Estatuto. Disponível em: http://www.justicaeleitoral.jus.br/arquivos/estatuto-do-partido-de-14-1-1996-resolucao-tseno.1997. Acesso em: 03 de outubro de 2018.

PITKIN, Hanna. El concepto de representación. Tradução de Ricardo Montoro Romero. Madrid: Centro de Estudios Constitucionales, 1995.

SARTORI, Giovanni. Partidos e sistemas partidários. Tradução de Waltensir Dutra. Rio de Janeiro: Editora Universidade de Brasília, 1982. 
SOBRAL NETO, Maurilo Miranda. Minoria Vermelha: Partidos Políticos Minoritários de Centro-Esquerda Como Agentes de Controle de Constitucionalidade. In: XXXIII Congresso Nacional de Pós-graduação em Direito (CONPEDI) - João Pessoa. Florianópolis: CONPEDI, p. 70-88, 2014.

TAROUCO, Gabriela. Partidos, programas e o debate sobre esquerda e direita no Brasil. Revista de Sociologia e Política, v. 21, n. 45, p. 149-165, 2013.

TAYLOR, Matthew M.; DA ROS, Luciano. Os partidos dentro e fora do poder: a judicialização como resultado contingente da estratégia política. Revista Dados, v. 51, n. 4, p. 825-864, 2008.

WHITTINGTON, Keith E.; KELEMEN, R. Daniel; CALDEIRA, Gregory A. (eds.) The Oxford handbook of law and politics. Oxford: Oxford University Press, 2008.

Data de Submissão: 03/01/2020

Data de Aceite: 03/03/2020 